\title{
A drug cost model for injuries due to road traffic accidents
}

Arthorn RIEWPAIBOON, Piyanuch PIYAUTHAKIT, Witsanuchai SRIJARIYA, Usa CHAIKLEDKAEW. Received (first version): 17-Aug-2007 Accepted: 22-Nov-2007

\begin{abstract}
*
Objective: This study aimed to develop a drug cost model for injuries due to road traffic accidents for patients receiving treatment at a regional hospital in Thailand.

Methods: The study was designed as a retrospective, descriptive analysis. The cases were all from road traffic accidents receiving treatment at a public regional hospital in the fiscal year 2004. Results: Three thousand seven hundred and twenty-three road accident patients were included in the study. The mean drug cost per case was USD18.20 ( $S D=73.49$, median=2.36). The fitted drug cost model had an adjusted $R^{2}$ of 0.449 . The positive significant predictor variables of drug costs were prolonged length of stay, age over 30 years old, male, Universal Health Coverage Scheme, time of accident during 18:00-24:00 o'clock, and motorcycle comparing to bus. To forecast the drug budget for 2006, there were two approaches identified, the mean drug cost and the predicted average drug cost. The predicted average drug cost was calculated based on the forecasted values of statistically significant $(p<0.05)$ predictor variables included in the fitted model; predicted total drug cost was USD44,334. Alternatively, based on the mean cost, predicted total drug cost in 2006 was USD63,408. This was $43 \%$ higher than the figure based on the predicted cost approach.

Conclusions: The planned budget of drug cost based on the mean cost and predicted average cost were meaningfully different. The application of a predicted average cost model could result in a more accurate budget planning than that of a mean statistic approach.
\end{abstract}

Keywords: Accidents, Traffic. Drug Costs. Thailand.

\section{UN MODELO DE COSTE DE MEDICAMENTOS PARA HERIDAS DEBIDAS A ACCIDENTES DE TRÁFICO}

\section{RESUMEN}

Objetivo: Este estudio trató de desarrollar un modelo de coste de medicamentos para las heridas debidas a los accidentes de tráfico en pacientes que reciben tratamiento en un hospital regional en Tailandia.

Métodos: Este estudio se diseñó como un análisis descriptivo retrospectivo. Los casos fueron todos los accidentes de tráfico que recibieron tratamiento en un hospital regional público en el año fiscal 2004.

Resultados: Se incluyeron en el estudio 3723 accidentes de tráfico. La media de coste por caso fue de 18,20 USD ( $\mathrm{DE}=73,49$, mediana=2.36). El modelo de ajuste de coste de medicamentos tenía un $R^{2}$ ajustado de 0,449 . Las variables significativamente predictivas positivas fueron la estancia prolongada, edad mayor de 30 años, hombre, Universal Health Coverage Scheme, hora del accidente de 18:00 a 24:00, y la motocicleta comparada con el autobús. Para predecir el presupuesto de medicamentos de 2006, se identificaron dos aproximaciones, el coste medio de medicamentos y el coste medio previsto de medicamentos. El coste medio previsto de medicamentos se calculó en base a los valores estadísticamente significativos $(\mathrm{p}<0,05)$ de las variables predictivas incluidas en el modelo de ajuste; el coste de medicamentos previsto fue de 44.334 USD. Alternativamente, en base al coste medio, el coste total de medicamentos previsto en 2006 fue de 63.408 USD. Este fue un $43 \%$ mayor que la cifra basada en el coste aproximado previsto. Conclusiones: El presupuesto planificado de de coste en medicamentos basado en la media del coste y el coste medio predicho eran sustancialmente diferentes. La aplicación de un modelo de coste medio predicho podría producir una planificación de presupuestos más ajustada que la aproximación estadística.

Arthorn RIEWPAIBOON, BPharm, PhD Associate Professor. Division of Social and Administrative Pharmacy, Department of Pharmacy, Faculty of Pharmacy, Mahidol University, Bangkok, (Thailand).

Piyanuch PIYAUTHAKIT B Pharm. Division of Social and Administrative Pharmacy, Department of Pharmacy, Faculty of Pharmacy, Mahidol University, Bangkok, (Thailand).

Witsanuchai SRIJARIYA MSc in Pharm. Division of Social and Administrative Pharmacy, Department of Pharmacy, Faculty of Pharmacy, Mahidol University, Bangkok, (Thailand).

Usa CHAIKLEDKAEW, B Pharm, PhD. Division of Social and Administrative Pharmacy, Department of Pharmacy, Faculty of Pharmacy, Mahidol University, Bangkok, (Thailand).
Palabras clave: Accidentes de tráfico. Costes de medicamentos. Tailandia. 


\section{INTRODUCTION}

In the past decade, road traffic accidents (RTAs) have become one of the top-ten leading causes of fatality in Thailand, a country with a 62.5 million population. ${ }^{1}$ The deaths from RTAs were $21.5,20.4$ and 19.8 per 100,000 populations for 2002, 2003 and 2004 , respectively. The rates of admission to government hospitals $(80.5 \%$ of total beds in the country in 2004) due to RTAs were $307.5,331.1$ and 334.2 per 100,000 populations in 2002, 2003 and 2004, respectively. ${ }^{2}$ Regarding health expenditure, the treatment expenditure due to road traffic injuries in 2000 was approximately 35,933 million THB or USD893 million (USD $1=40.22$ Thai baht; THB). Based on a recently report, the total health expenditure in 2002 was approximately 333,765 million THB or USD 7,762 million (USD $1=$ 43.00 THB). The drug expenditure was estimated at 66,827 million THB or USD 1554 million at Thai wholesale prices or 120,289 million THB or USD2797 million at Thai retail prices. This accounted for $36.04 \%$ of the total health expenditure or $2.21 \%$ of gross domestic products (GDP). ${ }^{3}$ This data illustrates that drug expenditure as a proportion of total health expenditure in Thailand is relatively high.

Hospitals in Thailand directly receive reimbursements from the Social Security Office, the Comptroller General's Department, and the National Health Security Office for private employees under the Social Security Scheme (SSS), the Civil Servants under the Medical Benefit Scheme (CSMBS), and the rest of the population under the Universal Coverage of Health Care Scheme (UC), respectively. The main reimbursement system is capitation for the SSS and UC, excluding the CSMBS, for a fee-for-service basis. ${ }^{4}$ This capitation system covers about 40 million people (approximately two-thirds of the Thai population). Based on these methods of financing health care, hospital administrators need economic data for efficient management.

Accordingly, we need to know the drug costs of road traffic accidents as supporting information for budget management and a planned road traffic injuries campaign. However, there are few studies on the costs of road traffic accidents in Thailand, and most of them are based on hospital charges, not costs. ${ }^{5-9}$ Therefore, it is important to know the drug costs of road traffic injuries in Thailand and their associated factors.

\section{METHODS}

This research was designed as a cost-of-illness study ${ }^{10}$ employing the prevalence-based approach from a provider's perspective. The costs included the acquisition drug cost due to the study illness, as well as complications, but did not include comorbidities. The study cases included were road traffic accident patients diagnosed as code V01 -
V89 in the International Classification of Diseases, 10th Revision (ICD-10). ${ }^{11}$ These patients were from a purposively selected hospital, Buddhachinaraj Hospital. It is a 904-bed public regional hospital, 377 kilometres north of Bangkok. All road traffic accident patients (both out-patients and in-patients) who received treatment during the fiscal year 2004 (October 1, 2003 - September 30, 2004) were included in the study. A sample size for the cost function analysis ${ }^{12}$ was calculated to confirm that the models were not underpowered.

$$
\begin{array}{ll}
\text { (1) } n \text { (at least) } & =30 \times I V \\
\text { where; } n & =\text { sample size } \\
I V & =\text { number of independent } \\
& \text { variables }
\end{array}
$$

Based on our review ${ }^{13}$, the factors affecting drug cost were hypothesized as follows:

(2) Drug cost $=f$ (demographic characteristic, accident type, service utilization)

From the hypothesis, there were 17 independent variables, so the minimum sample size was 510 cases. The variables included in this study are presented in Table 1. They consisted of the following: demographic characteristics including gender, age, and health insurance scheme; accident characteristics including type of vehicles involved and time of accident; and medical service utilization including hospitalization days and drug costs. The total drug cost was calculated by the summation of the results of multiplying the quantities of each drug and its acquisition unit cost at 2004 prices.

The data were retrospectively retrieved from the hospital database. Descriptive statistics were used to summarize the dependent and independent variables. Stepwise multiple regression analysis ${ }^{14}$ was employed to analyze the relationship between the drug cost (dependent variable) and potential predictor variables (independent variables). In the forward stepwise regression model, independent variables with a probability value of $F$ statistics $<0.05$ on the analysis were entered and those with $>0.10$ were removed. The statistical assumptions and models were examined for the following: normal distribution, homoscesdasticity, multicollinearity, influential observations, and outliers. ${ }^{14}$

\section{RESULTS}

\section{Patient characteristics and drug utilization}

Three thousand seven hundred and twenty-three patients were analyzed. The majority of patients were male $(69.3 \%)$. The mean age of those involved was 31.28 years $(S D=16.98)$, and most of the patients were younger than 30 years of age $(55.2 \%)$. Approximately half of the patients $(52.7 \%)$ received treatment as in-patients. Most payments (54.4\%) were under the Universal Health Coverage Scheme (UC), followed by out-of-pocket (26.6\%), Civil Servants Medical Benefit Scheme (CSMBS) (12.2\%), Social Security Scheme (SSS) (6.7\%), and Motor Vehicle Accident Victim Protection Insurance $(0.1 \%)$. Additionally, the vehicle involved in most of the patients' accident was the motorcycle $(77.7 \%)$. 
The total drug costs of all cases $(n=3,723)$ was $2,725,206.65$ THB or USD $67,757.50$ (average exchange rate in $2004 ;{ }^{15}$ USD $1=40.22$ Thai baht; THB). The mean drug cost was 731.99THB (USD
18.20) per patient with a median of 95.00 THB (USD 2.36). The 95\% confidence interval was 637.01 THB (USD 15.84) to 826.97 THB (USD 20.56).

\begin{tabular}{|c|c|}
\hline \multicolumn{2}{|c|}{ Variable and sample characteristics } \\
\hline Ln_Cost & Natural logarithm of drug cost (THB) \\
\hline LOS & Length of stay; mean 2.89 days \\
\hline Male & Equals 1 if male; $69.3 \%(0=$ female $)$ \\
\hline UC & $\begin{array}{l}\text { Equals } 1 \text { if patients were under health insurance schemes other than the UC; } 54.4 \%(0 \\
=\text { Universal Health Coverage Scheme; UC ) }\end{array}$ \\
\hline \multicolumn{2}{|c|}{ Age of patients; reference was $31-60$ years of age $(38.6 \%)$} \\
\hline Age_1-12 & Equals 1 if aged $1-12$ years; $9.2 \%(0=$ else $)$ \\
\hline Age_13-18 & Equals 1 if aged $13-18$ years; $17.2 \%(0=$ else $)$ \\
\hline Age $19-30$ & Equals 1 if aged $19-30$ years; $28.8 \%(0=$ else $)$ \\
\hline Age_60 up & Equals 1 if aged more than 60 years; $6.2 \%(0=$ else $)$ \\
\hline \multicolumn{2}{|c|}{ Accidental time; reference was from 6 am- 6 pm (48.4\%). } \\
\hline Time_18-24 & Equals 1 if accident occurred between $6-12 \mathrm{pm} ; 40.3 \%(0=$ else $)$ \\
\hline Time_0-6 & Equals 1 if accident occurred between $12 \mathrm{mn}-6 \mathrm{am} ; 11.3 \%(0=$ else $)$ \\
\hline \multicolumn{2}{|c|}{ Accidental vehicles; reference was motorcycle $(77.7 \%)$} \\
\hline Vehicle_Car & Equals 1 if car; $6.5 \%(0=$ else $)$ \\
\hline Vehicle_Tuk & Equals 1 if 3 -wheeled motorcycle; $3.6 \%(0=$ else $)$ \\
\hline Vehicle_Truck & Equals 1 if heavy truck; $1.1 \%(0=$ else $)$ \\
\hline Vehicle_Bus & Equals 1 if bus; $0.8 \%(0=$ else $)$ \\
\hline Pedestrian & Equals 1 if pedestrian; $10.4(0=$ else $)$ \\
\hline
\end{tabular}

\begin{tabular}{|l|c|c|c|c|c|c|}
\hline \multirow{2}{*}{ Table 2 Fitted explanatory model of drug costs } \\
& $\begin{array}{c}\text { Unstandardized } \\
\text { Coefficients }\end{array}$ & & & \multicolumn{2}{|c|}{$\begin{array}{c}\text { 95\% Confidence Interval } \\
\text { for } B\end{array}$} \\
\cline { 2 - 7 } & $B$ & $\begin{array}{c}\text { Std. } \\
\text { Error }\end{array}$ & $t$ & Sig. & Lower Bound & Upper Bound \\
\hline (Constant) & 3.789 & 0.065 & 58.714 & 0.000 & 3.662 & 3.915 \\
\hline LOS & 0.241 & 0.006 & 43.574 & 0.000 & 0.230 & 0.252 \\
\hline Age_1-12 & -0.962 & 0.092 & -10.457 & 0.000 & -1.143 & -0.782 \\
\hline Male & 0.386 & 0.055 & 7.026 & 0.000 & 0.278 & 0.493 \\
\hline UC & 0.274 & 0.051 & 5.332 & 0.000 & 0.173 & 0.374 \\
\hline Age_13-18 & -0.335 & 0.070 & -4.778 & 0.000 & -0.473 & -0.198 \\
\hline Time_18-24 & 0.127 & 0.051 & 2.477 & 0.013 & 0.027 & 0.228 \\
\hline Vehicle_Car & 0.224 & 0.103 & 2.174 & 0.030 & 0.022 & 0.426 \\
\hline Vehicle_Bus & -0.603 & 0.277 & -2.179 & 0.029 & -1.146 & -0.060 \\
\hline Age_19-30 & -0.129 & 0.060 & -2.157 & 0.031 & -0.246 & -0.012 \\
\hline
\end{tabular}

\section{Drug cost model}

The cost model was formulated as an explanatory model. Drug cost as the dependent variable was not normally distributed. Therefore, a natural logarithmic transformation was undertaken. The predictor variable definitions are presented in Table 1. Table 2 shows the fitted explanatory model with the adjusted $R^{2}=0.449$ and a probability-value of $F$ statistics $<0.001$. Thus, forty-five percent of the variations in drug costs could be explained by the variables included in the model. The significant predictor variables of drug costs were prolonged length of stay, age group (Younger aged patients were associated with lower costs than middle aged adults.), gender (male), Universal Coverage scheme (UC), time of accident (18:00 - 24:00 o'clock), and type of vehicle (Bus use was associated with a reduction in costs compared to motorcycles). The model met the model checking criteria (Durbin-Watson $=1.911$, Leverage statistics $=0.004$, Cook's distance $=0$, VIF $<1.21$, Tolerance $>0.826$, Condition index <5.95). ${ }^{14}$ The fitted model of drug cost is presented as follows:
(3) $L n c o s t=3.789+0.241$ LOS -0.962 Age_1-12 +0.386 Male + 0.274 UC - 0.335 Age_13-18

+ 0.127 Time_18-24 + 0.224 Vehicle_Car - 0.603 Vehicle Bus - 0.129 Age 19-30

Alternatively, the model is presented in the following form: ${ }^{16}$

(4) $L n \_$Cost $=3.789+(0.241 \times$ Length of stay $)$ -

(0.962x\% Patients age $1-12$ years)- $(0.335 \times \%$

Patients age $13-18$ years)-(0.129x\% Patients age $19-30$ years $)+(0.386 \times \%$ Male

patients $)+(0.274 \times \%$ Patients under UC

scheme $)+(0.127 x \%$ Patients during 6 -

$12 \mathrm{pm})+(0.224 x \%$ Patients due to car accidents $)$ -

( $0.603 x \%$ Patients due to bus accidents)

To estimate the expected response on an untransformed scale after fitting a linear regression model of a transformed scale, there is a need to adjust it by the smearing factor. ${ }^{17,18}$ The smearing factor of the drug cost model in this study was 2.7363 .

To forecast the budget for the drug supply in 2006, based on our model, we expect to have a $10 \%$ decrease in road accident-related cases due to the 
national road safety campaign focusing on motorcycling behavior. The expected number is 3,350 cases, with an average patient population of $70 \%$ male, five days of hospitalization, $10 \%$ age 1 12 years, $30 \%$ age $13-18$ years, $20 \%$ age $19-30$ years, $45 \%$ under the Universal Coverage of Health Care Scheme, 50\% accidents occurring from 6-12 pm, $20 \%$ car accidents, and $5 \%$ bus accidents. The expected inflation rate between 2004 and 2006 for medical care is $4 \%$. The calculation was initially done byplacing the value of the individual predictor variable into the model to multiply it with the coefficient resulting in the cost caused by the variable. Then, the summation of the costs was exponentiated, resulting in the cost in anti-log form. This method was applied elsewhere. ${ }^{16}$ This cost was adjusted by multiplying with the smearing factor followed by the inflation rate. Finally, the predicted drug cost per patient is 554 THB at 2006 prices. The predicted total drug cost in 2006 is $1,783,115$ THB or USD 44,334. The calculation of the predicted cost is illustrated in Table 3.

\begin{tabular}{|c|c|c|c|}
\hline 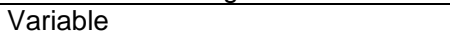 & Coefficient & Parameter value & Cost \\
\hline Constant & 3.789 & 1 & 3.79 \\
\hline Length of stay (days) & 0.241 & 5 & 1.21 \\
\hline Patients aged $1-12$ years & -0.962 & 0.1 & -0.10 \\
\hline Patients aged $13-18$ years & -0.335 & 0.3 & -0.10 \\
\hline Patients aged $19-30$ years & -0.129 & 0.2 & -0.03 \\
\hline Male patients & 0.386 & 0.7 & 0.27 \\
\hline Patients with the UC & 0.274 & 0.55 & 0.15 \\
\hline Accident between 6-12 pm & 0.127 & 0.5 & 0.06 \\
\hline Car accident & 0.224 & 0.2 & 0.04 \\
\hline Bus accident & -0.603 & 0.05 & -0.03 \\
\hline Cost in log form (summation) & $\mathrm{n} / \mathrm{a}$ & $\mathrm{n} / \mathrm{a}$ & 5.27 \\
\hline Predicted cost (anti-log form; THB) & $\mathrm{n} / \mathrm{a}$ & $\mathrm{n} / \mathrm{a}$ & 194.52 \\
\hline Smearing factor & $\mathrm{n} / \mathrm{a}$ & $\mathrm{n} / \mathrm{a}$ & 2.74 \\
\hline Adjusting predicted cost (THB) & $\mathrm{n} / \mathrm{a}$ & $\mathrm{n} / \mathrm{a}$ & 532.27 \\
\hline Inflation rate & $\mathrm{n} / \mathrm{a}$ & $\mathrm{n} / \mathrm{a}$ & $4 \%$ \\
\hline Cost at 2006 (THB) & $\mathrm{n} / \mathrm{a}$ & $\mathrm{n} / \mathrm{a}$ & 553.56 \\
\hline Number of patients & $\mathrm{n} / \mathrm{a}$ & $\mathrm{n} / \mathrm{a}$ & $3,350.00$ \\
\hline Total drug cost (THB) & $\mathrm{n} / \mathrm{a}$ & $\mathrm{n} / \mathrm{a}$ & $1,783,114.78$ \\
\hline Total drug cost (US $\$$ ) & $\mathrm{n} / \mathrm{a}$ & $\mathrm{n} / \mathrm{a}$ & $44,334.03$ \\
\hline
\end{tabular}

\section{DISCUSSION}

The mean drug cost is USD 18.20 while the median is USD 2.36. This indicated that the sample data is skewed to the right. The drug cost has a similar nature to that of health care cost. A small proportion of patients incur extremely high costs relative to most patients. ${ }^{19}$ Particularly in this study, the samples were injured patients from various types of road traffic accidents including both outpatients and in-patients, with approximately half being out-patients. Therefore, most of the patients' symptoms might only have mild severity, even though the study hospital is a regional tertiary hospital. In addition, the hospital employed physicians with specialties and sub-specialties. Perhaps physicians trained as specialists or subspecialists may be more likely to use expensive drugs from international pharmaceutical companies that must be imported into Thailand. The prices of these drugs are much higher than domestically produced drugs. Therefore, the average cost might not be generalizable to other Thai hospitals, particularly the district hospitals. The fitted model of drug cost presented in Equation 3 is explained by the following independent variables. Three age groups between 1-30 years had a negative effect compared to the age group of 31-60 years. This means that patients aged between 31-60 years had higher drug costs than the other age groups. This might be because adult patients receive higher doses of drugs than do children. This study did not account for accident severity, though cost may be positively associated with levels of severity. Thus, it could be that adult patients were admitted with more severe injuries than other age groups. For gender, the male patients showed higher costs than the female patients. This could be explained by the fact that male patients tend to be drunk drivers and exhibit a more aggressive driving behavior, thus resulting in more severe injuries. The patients under the Universal Health Coverage Scheme (UC) had lower costs than other insurance schemes. This might be an effect of the health financing methods. Public hospitals in Thailand receive a fixed per-capita budget per person registered to the UC. The physicians are urged to control expenditure of such patients. This phenomenon is demonstrated in other studies. ${ }^{13,22-}$ ${ }^{24}$ Similarly, the effect of insurance schemes on drug costs has been published in the United States. ${ }^{16}$ Regarding to vehicle types, injuries due to bus accidents had less costs in contrast to motorcycle accidents. It was found that only $10 \%$ of patients due to motorcycle accidents wore helmets. ${ }^{25}$ Therefore, these patients had a tendency to have a higher accident severity. Considering the time of the accidents, it was found that patients whose 
accidents occurred during the evening (6-12 pm) had more drug costs than those whose accidents occurred at other times. This might be related to the drunk-driving behavior. There was a study that reported on severity of injuries and methods of transfer to the hospital as having an effect on hospitalization. ${ }^{26}$ These factors were not included in this study. For future studies, the addition of such variables to the model might increase the power of the model's explanation. This is because hospitalization has more effect on drug use than those of ambulatory services.

Management of the drug supply is one of the pivotal activities in the health care system and covers the selection, procurement, distribution, and use of the drugs. ${ }^{27}$ Estimating future drug consumption is an important part of drug supply management. Conventionally, there are three methods of estimating drug requirements (i.e., population-based estimates, service-based estimates, and consumption-based estimates). ${ }^{27}$ Population-based estimates consider the epidemiological assessment of a country's most important diseases and health problems. Service-based estimates are based on the number of services provided by the program. Consumption-based estimates take into account previous utilization records.

The predicted total drug cost in 2006 is $1,783,115$ THB or USD44,334 as illustrated in Table 3. Conventionally, the total cost is estimated as an arithmetic mean multiplied by the number of patients. $^{28}$ The mean cost is adjusted by the inflation rate. Then, the total drug cost in 2006 would be $731.99 \times 1.04$ THB $\times 3,350$ cases $=$ $2,550,253$ THB or USD63,408. The difference is USD 19,074 or $43 \%$ higher than that of the predicted cost approach. The variation of the forecasted budget is quite large. The predicted average drug costs from the fitted model are calculated based on the forecasted epidemiological data resulting from the road safety campaign. This would result in a more accurate budget planning than that of forecasting based on only the mean statistic. This technique has been applied elsewhere. ${ }^{16,29}$
However, the exact model is not directly exportable for use at other hospitals, although the methodology is. This can be explained by the following reasons. First, drug costs change over time, it is not static. Even if the variables remain constant, the coefficient values of the variable will change over time. Second, the parameters in the model are specific to the population studied. In different population characteristics, different variables may be more predictive of drug costs than the ones tested in this study. $^{16}$ In addition, it is essential to note that the variation of cost among organizations is based on price variances (prices of resources used), efficiency variances (resource use behavior), and volume variances (output production). ${ }^{30}$

\section{CONCLUSIONS}

Based on the fitted model, the significant predictor variables include patient characteristics (age, gender, and health insurance schemes), accident characteristics (type of vehicle and time of accident) and hospital service utilization (hospitalization days). The predicted average drug cost from the fitted model and the epidemiological forecast resulting from the road safety campaign will provide a more accurate budget planning than that of forecasting based on a mean statistic. Therefore, the cost model could be employed as a hospital financial management tool.

\section{ACKNOWLEDGMENTS}

We would like to thank the director and the hospital staff of the Buddhachinaraj Hospital. We would also like to extend our appreciation to Mr. Perry Whalley, the Language Center, Faculty of Graduate Studies, Mahidol University for his advice on manuscript presentation.

\section{CONFLICT OF INTEREST}

None declared. Contract grant sponsor: The Health Promotion Foundation, Bangkok, Thailand.

\section{References}

1. Sintuvanich A. The impact of industrialization on road traffic accidents in Thailand. J Med Assoc Thai. October 1, 1997 1997;80(10):631-635.

2. Alpha Research, ed. Thailand public health 2006-2007. Nonthaburi: Alpha Research; 2006.

3. Wibulpolprasert S, ed. Thailand health profile 2001-2004. Bangkok: Bureau of Policy and Strategy, Ministry of Public Health; 2005.

4. Srithamrongsawat S. Progress and achievement: universal coverage of health care scheme annual report 2004. Bangkok: National Health Security Office; 2004.

5. Tosutho R. Economic loss and road accident related factors [Master of Science in Health Economics]. Bangkok: Department of Economics, Chulalongkorn University; 1997.

6. Pitagpravej T. [Economic losses due to transport accidents] (in Thai Language). J Health Science. 1997;6(2):185-193.

7. Podhipak A. The study of costs of road accident among patients admitted in the general hospitals: Bangkok metropolitan area [Master of Science in Public Health]. Bangkok, Mahidol University; 1996.

8. Pulpanyawong K, Somboonkul S, Chadthong K. Epidemiologic characteristics of road traffic injuries in Chumphon Hospital, March-August 1997 (in Thai Language). J Health Science. 1998;7(3):311-318.

9. Suriyawongpaisal $P$, Kanchanasut $S$. Road traffic injuries in Thailand: trends, selected underlying determinants and status of intervention. Inj Control Saf Promot. 2003;10(1-2):95-104.

10. Kobelt G. Health economics: an introduction to economic evaluation. second ed. London: Office of Health Economics; 2002. 
11. World Health Organization. ICD-10: International statistical classification of diseases and related health problems tenth revision. Geneva: World Health Organization; 1992.

12. Lwanga SK, Lemeshow S. Sample size determination in health studies: a practical manual. Geneva: World Health Organization; 1991.

13. Munnae K. Factors affecting drug and other treatment expenditure in traffic accident patients [M.S. Thesis in Pharmacy (Pharmacy Administration)]. Bangkok: Faculty of Graduate studies, Mahidol University; 1999.

14. Cohen J, Cohen P, West SG, Aiken LS. Applied multiple regression/ correlation analysis for the behavioral sciences Third ed. New Jersey: Lawrence Erlbaum Associates, Inc.; 2003.

15. Bank of Thailand. Foreign Exchange Rates Bank of Thailand. Available at: http://www.bot.or.th/bothomepage/databank/FinMarkets/ExchangeRate/exchange_e.asp. Accessed February 5, 2007.

16. Petitta A, Patel RP, Zarowitz BJ. Developing a drug-cost model for a capitated patient population in an integrated health care system. Am J Health Syst Pharm. 2002;59(2):143-146.

17. Duan N. Smearing estimator: a nonparametric retransformation method. J Am Stat Assoc. 1983;78(383):605-610.

18. Smith M, Barnett $P$. What is retransformation bias, and how can it be corrected? Available at: www.herc.research.med.va.gov/faqE2_retransformation.pdf Accessed August 5, 2005.

19. Zhou X-HA, Ramsey S. Assessing the equality of means of healthcare costs. Expert Rev Pharmacoeconomics Outcomes Res. 2003;3(5):561-567.

20. Hendrie D, Rosman DL, Harris AH. Hospital inpatient costs resulting from road crashes in Western Australia. Aust $J$ Public Health. 1994;18(4):380-388.

21. Langley JD, Phillips D, Marshall SW. Inpatient costs of injury due to motor vehicle traffic crashes in New Zealand. Accid Anal Prev. 1993;25(5):585-592.

22. Chaikledkaew U, Pongcharoensuk P, Ongphiphadhanakul B, Chaiyakunapruk N. Factors associated with healthcare expenditures and hospitalizations in Thai patients with diabetes at four public hospitals. Mahidol Univ J Pharm Sci. 2005;32:1-6.

23. Riewpaiboon A, Intraprakan K, Phoungkatesunthorn S. Predicting treatment cost of bacterial diarrhea at a regional Hospital in Thailand. Bangkok: Faculty of Pharmacy, Mahidol University; 2007.

24. Riewpaiboon A, Youngkong S, Sreshthaputra N, Stewart JF, Samosornsuk S, Chaicumpa W, et al. A cost function analysis of shigellosis in Thailand. Value in Health 2008 (accepted).

25. Thanaboriboon Y. Risk factors of road traffic accident (in Thai language). Health situation in Thailand. 2006;2(10):1-6.

26. Jirojwong S, Rudtanasudjatum K, Watcharavitoon P, Sathitsathien W, Sangjun S. Non-fatal injuries sustained in road traffic accidents: a pilot study in provincial hospitals in Chon Buri, Thailand. Southeast Asian J Trop Med Public Health. 2002;33(1):193-200.

27. Bates J, Henk dB, Cross PN, Dias V, Hartman AF, Hewitt W, et al. Managing drug supply; the selection, procurement, distribution, and use of pharmaceuticals in primary health care. Boston: Management Sciences for Health; 1981.

28. Barber JA, Thompson SG. Analysis and interpretation of cost data in randomised controlled trials: review of published studies. BMJ. 1998;317:1195-1200.

29. Hoffman JM, Shah ND, Vermeulen LC, Hunkler RJ, Hontz KM. Projecting future drug expenditures--2005. Am J Health Syst Pharm. 2005;62:149-167.

30. Shepard DS, Hodgkin D, Anthony YE. Analysis of hospital costs: a manual for managers. Geneva: The World Health Organization; 2000. 